\title{
Strategi Perbaikan Implementasi Manajemen Keselamatan dan Kesehatan Kerja (K3) TPAS Wisata Edukasi Talangagung Kabupaten Malang
}

\author{
Dhymas Sulistyono Putro \\ Program Studi Teknik Lingkungan Universitas Muhammadiyah Palangka Raya, Palangka Raya \\ *Koresponden email: dhymassulistyono95@gmail.com
}

Diterima: 27 Mei 2021

Disetujui: 11 Juni 2021

\begin{abstract}
The operation of the Talangagung Edu-Tourism Landfill applies a sanitary landfill system, which requires a workforce to operate optimally. These workers may be exposed to work accidents and occupational diseases when the Landfill is operating, which come from various sources of OHS hazards. Efforts to reduce the risk of work accidents and occupational diseases consist of managing OHS in the working environment of the Talangagung Edu-Tourism Landfill. The goal of this study is to evaluate the application and provide recommendations to improving the application of OHS management at the Edu-Tourism Landfill in Talangagung. Thus, the Talangagung Edu-Tourism Landfill can maximize the volume of waste and educational tourism facilities. This study involved 16 respondents who were divided into workers and decision-makers by selective sampling in the operation of the Talangagung Edu-Tourism Landfill with data collection by observation, interviews, and questionnaires. The results of this study show that the Talangagung Edu-Tourism Landfill has implemented OHS management but the need to formulate new OHS management, to achieve maximum results. The priority strategy in efforts to improve OHS management is to "enhance awareness of OHS management" where there is a plan to implement the strategy to facilitate implementation of the strategy in the work environment.
\end{abstract}

Keywords: landfill, management, OHS, strategy, SWOT

\begin{abstract}
Abstrak
Operasional TPAS Wisata Edukasi Talangagung menerapkan sistem sanitary landfill, yang membutuhkan tenaga kerja agar dapat berjalan secara optimal. Tenaga kerja tersebut berpotensi memiliki risiko kecelakaan kerja dan penyakit akibat kerja saat TPAS beroperasional, yang berasal dari berbagai sumber bahaya K3. Upaya dalam menurunkan risiko kecelakaan kerja dan penyakit akibat kerja (PAK) yaitu menjalankan Manajemen K3 di lingkungan kerja TPAS Wisata Edukasi Talangagung. Tujuan dalam penelitian ini yaitu mengevaluasi penerapan dan memberikan rekomendasi perbaikan penerapan manajemen K3 di lingkungan TPAS Wisata Edukasi Talangagung. Sehingga, TPAS Wisata Edukasi Talangagung dapat memaksimalkan volume sampah dan sarana wisata Pendidikan. Penelitian ini melibatkan 16 responden yang terbagi menjadi tenaga kerja dan pengambil keputusan secara purposive sampling dalam operasional TPAS Wisata Edukasi Talangagung dengan pengumpulan data secara observasi, wawancara, dan kuesioner. Hasil penelitian ini diketahui TPAS Wisata Edukasi Talangagung telah menerapkan manajemen K3 akan tetapi perlu merumuskan manajemen K3 baru, agar mendapatkan hasil yang lebih maksimal. Strategi prioritas dalam upaya perbaikan manajemen K3 yaitu "peningkatan kesadaran manajemen K3" dimana terdapat rencana implementasi strategi untuk memfasilitasi implementasi strategi di lingkungan kerja.
\end{abstract}

Kata Kunci: TPAS, K3, Manajemen, Strategi, SWOT

\section{Pendahuluan}

Sampah merupakan produk samping dari aktivitas manusia dalam kesehariannya [1]. Tanpa pengelolaan yang tepat, berpotensi menurunkan kualitas lingkungan [2]. Pengelolaan sampah di Indonesia dikelola dengan pembangunan Tempat Pemrosesan Akhir Sampah (TPAS). Salah satu penerapan TPAS di Kabupaten Malang yaitu TPAS Wisata Edukasi Talangagung. Operasional TPAS Wisata Edukasi Talangagung menerapkan sistem sanitary landfill, dimana membutuhkan tenaga kerja agar berjalan secara maksimal. Tenaga kerja ini dapat dipastikan memiliki risiko kecelakaan kerja dan penyakit akibat kerja (PAK) saat TPAS beroperasi yang berasal dari berbagai sumber bahaya K3. Sumber bahaya K3 yang menyertai pekerja dapat berupa adanya penurunan kualitas udara, air, tanah, serta lingkungan kerja di TPAS Wisata Edukasi Talangagung [3]. Adanya $\mathrm{H}_{2} \mathrm{~S}, \mathrm{NH}_{3}$, dan $\mathrm{CH}_{4}$ hasil pemrosesan sampah akan mengganggu 
saluran pernapasan tenaga kerja [4]. Penurunan kualitas tanah akan terjadi karena adanya Timbal ( $\mathrm{Pb})$ [5]. Selain itu, TPAS Wisata Edukasi Talangagung merupakan sarana edukasi di Kabupaten Malang, sehingga perlu adanya perlindungan kepada tenaga kerja maupun wisatawan. Salah satu bentuk perlindungan awal yang dapat diterapkan yaitu Manajemen K3 tenaga kerja di lingkungan TPAS Wisata Edukasi Talangagung [6].

Penerapan Manajemen K3 menghasilkan aspek keselamatan, yang secara langsung akan meningkatkan aspek kesehatan tenaga kerja. Adanya Penerapan Manajemen K3 di lingkungan kerja TPAS Wisata Edukasi Talangagung akan menurunkan risiko kecelakaan kerja dan PAK yang akan berdampak pada peningkatan produktivitas kerja [7]. Sehingga, TPAS Wisata Edukasi Talangagung mampu menurunkan volume sampah dan sarana wisata edukasi secara maksimal.

Lingkungan kerja TPAS belum sepenuhnya menerapkan manajemen K3 serta belum adanya regulasi yang mengatur. Dimana, pada penelitian sebelumnya hanya menghasilkan dampak TPAS terhadap kesehatan tenaga kerja. Belum adanya regulasi tersebut, pihak pengelola atau pengambil keputusan TPAS Wisata Edukasi Talangagung perlu merumuskan strategi perbaikan dalam implementasi manajemen K3, sehingga penerapan Manajemen K3 dapat berjalan secara optimal [8].

\section{Metode Penelitian \\ Lokasi Penelitian}

Pelaksanaan penelitian ini di TPAS Wisata Edukasi Talangagung Desa Talangagung, Kecamatan Kepanjen, Kabupaten Malang, Provinsi Jawa Timur. Secara astronomi terletak di 8o07'14.18' Lintang Selatan dan 112o 33'43.00 dari Bujur Timur. TPAS ini sepenuhnya dikelola oleh Dinas Lingkungan Hidup (DLH) Kabupaten (Kab) Malang.

\section{Pengumpulan Data}

Data dalam penelitian ini dikumpulkan melalui observasi, wawancara, dan kuesioner. Pengamatan dan wawancara, dan kuesioner bertujuan untuk mengidentifikasi faktor lingkungan internal dan eksternal. Kuesioner juga berfungsi dalam pembobotan dan rating masing-masing faktor lingkungan. Faktor lingkungan memiliki variabel berupa keuangan, sumber daya manusia, penelitian dan pengembangan, yang terdiri atas politik dan kebijakan pemerintah, serta teknologi yang diterapkan. Variabel-variabel tersebut menjadi dasar dalam penyusunan kuesioner dengan menggunakan skala Likert. Kuesioner identifikasi faktor lingkungan melibatkan 13 orang tenaga kerja, sedangkan kuesioner pembobotan dan rating melibatkan 3 orang pengambil keputusan dalam operasional TPAS Wisata Edukasi Talangagung. Penentuan responden didasarkan pada responden ahli yang dipilih secara purposive sampling [9]. Responden ahli merupakan responden yang terlibat dalam kegiatan atau sistem secara langsung.

\section{Analisis Data}

Hasil pembobotan dan rating didasarkan pada kuesioner. Pembobotan berasal dari perbandingan tingkat kepentingan antara faktor lingkungan (perbandingan berpasangan), sehingga menghasilkan skor penilaian. Hasil skor tersebut akan dirumuskan menggunakan matriks Internal-Eksternal (IE). Matriks IE akan mempermudah penentuan strategi alternatif dalam analisis SWOT. Faktor lingkungan internal dan eksternal yang teridentifikasi digunakan dalam merumuskan strategi perbaikan penerapan manajemen K3 di TPAS Wisata Edukasi Talangagung menggunakan analisis SWOT. Faktor lingkungan internal tersusun atas kekuatan dan kelemahan di TPAS Wisata Edukasi Talangagung. Sedangkan faktor lingkungan eksternal tersusun atas peluang dan ancaman di TPAS Wisata Edukasi Talangagung. Alternatif strategi yang telah dirumuskan dalam analisis SWOT, dilakukan penentuan strategi prioritas dalam implementasi manajemen K3 di lingkungan kerja TPAS Wisata Edukasi Talangagung. Perumusan perencanaan implementasi strategi bertujuan untuk mempermudah implementasi strategi. Perencanaan implementasi strategi dibagi berdasarkan program, kegiatan, dan keluaran yang dihasilkan.

\section{Hasil dan Pembahasan \\ Identifikasi Faktor Lingkungan}

Hasil identifikasi faktor lingkungan terbagi menjadi 3 faktor lingkungan kekuatan, 2 faktor lingkungan kelemahan, 2 faktor lingkungan peluang, dan 2 faktor lingkungan ancaman. Faktor lingkungan merupakan faktor penunjang dalam perbaikan manajemen risiko K3 TPAS Wisata Edukasi Talangagung [9][10][11]. Hasil identifikasi faktor lingkungan tertera pada Tabel 1. 
Tabel 1. Hasil Identifikasi Faktor Lingkungan

Faktor Lingkungan Internal

\section{Kekuatan}

Ketersediaan anggaran untuk pelaksanaan K3 (S1)

Tenaga kerja mengetahui sumber bahaya K3 dan risiko kecelakaan kerja di lingkungan kerjanya (S2)

Minimnya pekerjaan/kegiatan yang membutuhkan keterampilann khusus (S3)

Kelemahan

Belum adanya tenaga ahli K3 dalam operasional TPAS Wisata Edukasi Talangagung (W1)

Belum adanya pelatihan Manajemen K3 terhadap tenaga kerja TPAS Wisata Edukasi Talangagung (W2)

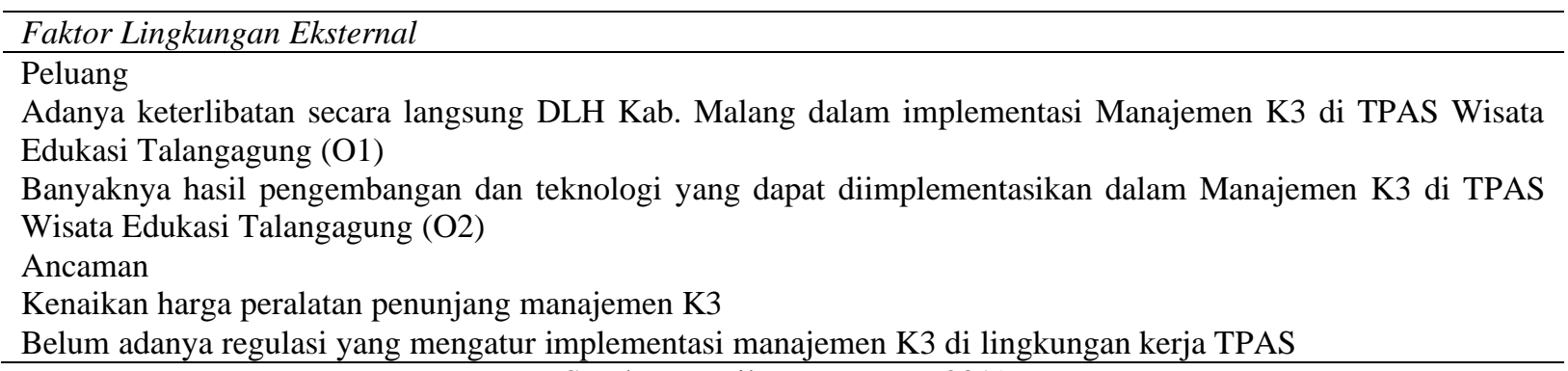
Sumber: Hasil pengamatan, 2019

\section{Pembobotan dan Rating Faktor Lingkungan}

Pembobotan dan rating faktor lingkungan merupakan tahapan penilaian faktor lingkungan dalam analisis SWOT. Skor yang diperoleh pada masing-masing faktor lingkungan merupakan hasil perkalian pembobotan terhadap rating. Hasil skor ini dapat menjadi acuan dalam memaksimalkan faktor lingkungan [12][13][14]. Hasil analisis faktor lingkungan internal (IFAS) tercantum pada Tabel 2 dan hasil analisis faktor lingkungan eksternal (EFAS) tercantum pada Tabel 3.

Tabel 2. Skor IFAS

\begin{tabular}{cccc}
\hline Faktor Lingkungan Internal & Pembobotan & Rating & Skor \\
\hline S1 & 0,143 & 2,667 & 0,382 \\
S2 & 0,187 & 3 & 0,560 \\
S3 & 0,187 & 2 & 0,375 \\
S4 & 0,148 & 3,667 & 0,543 \\
W1 & 0,159 & 2,667 & 0,425 \\
W2 & 0,175 & 4 & 0,701 \\
Total & & & 2,986 \\
\hline
\end{tabular}

Sumber: Hasil analisis, 2019

Tabel 3. Skor EFAS

\begin{tabular}{llll}
\hline Faktor Lingkungan Eksternal & Pembobotan & Rating & Skor \\
\hline O1 & 0,198 & 3 & 0,594 \\
O2 & 0,185 & 2,667 & 0,493 \\
T1 & 0,337 & 3,333 & 1,123 \\
T2 & 0,280 & 2,667 & 0,747 \\
Total & & & 2,957 \\
\hline
\end{tabular}

Sumber: Hasil analisis, 2019

\section{Matriks IE}

Matriks ini berfungsi untuk mengetahui posisi TPAS Wisata Edukasi Talangagung dalam meningkatkan penerapan manajemen K3. Mengetahui posisi tersebut, akan membantu dalam perumusan strategi peningkatan penerapan Manajemen K3 [15]. Hasil Matriks IE dapat dilihat pada Gambar 1. 
IFAS Total

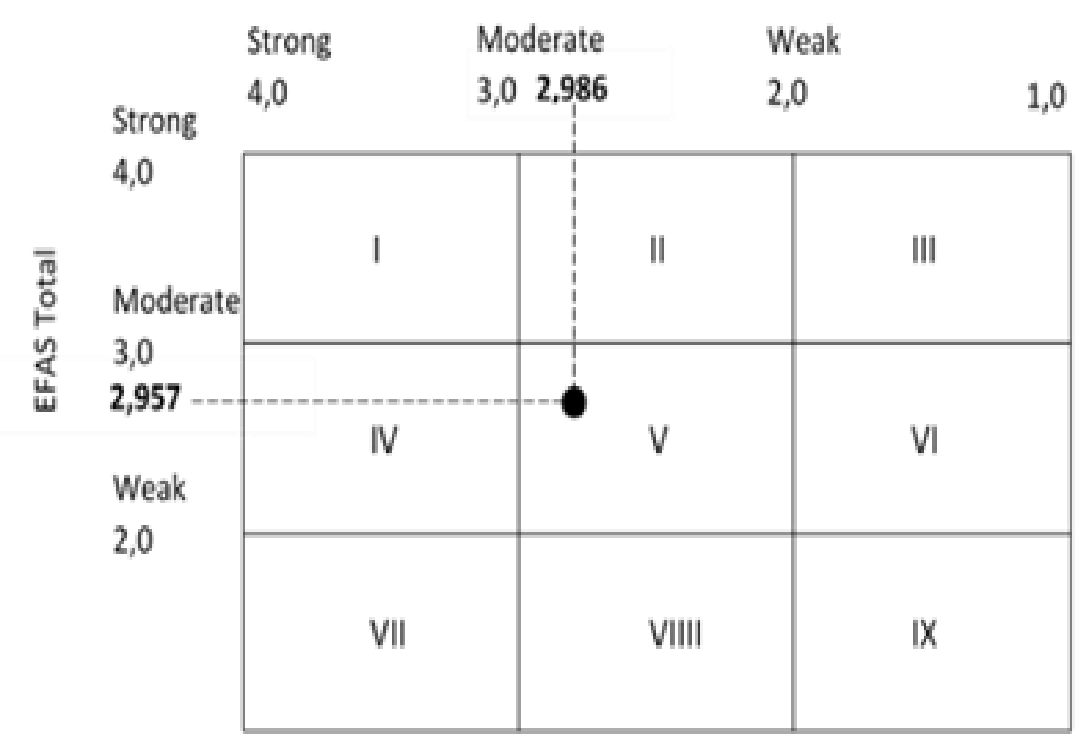

Gambar 1. Hasil Matriks IE

Sumber: Hasil analisis, 2019

Hasil pembahasan sebelumnya skor IFAS sebesar 2,986 dan skor EFAS 2,957. Sehingga menempatkan implementasi manajemen K3 TPAS Wisata Edukasi Talangagung pada sel V. Sel III, V, dan VII dikategorikan sebagai strategi Keep and Maintain, maka TPAS Wisata Edukasi Talangagung perlu adanya penyelenggaraan dan mengelola manajemen K3 yang saat ini telah diterapkan [16][17].

\section{Analisis SWOT}

Penerapan strategi memiliki tujuan tersendiri, yaitu menggunakan faktor kekuatan dan peluang dalam meminimalisir faktor kelemahan dan ancaman [18][19]. "Meninjau peralatan yang akan digunakan dalam implementasi OHS" dikategorikan ke dalam strategi kekuatan-peluang (SO). Keterlibatan DLH Kab. Malang pada operasional akan memudahkan dalam perumusan dan penggunaan peralatan manajemen K3 yang berbasis pada pengembangan dan teknologi yang tepat. Strategi kedua adalah "meningkatkan kesadaran manajemen K3". Strategi ini dikategorikan sebagai strategi kelemahan-peluang (WO). DLH Kab. Malang merupakan instansi pemerintah yang dapat memfasilitasi rekrutmen tenaga ahli K3 sekaligus mampu menyelenggarakan pelatihan manajemen K3 kepada seluruh tenaga kerja TPAS Wisata Edukasi Talangagung.

Adanya pelatihan K3 terhadap tenaga kerja akan meningkatkan pemahaman K3 di lingkungan kerja [20][21]. "Penetapan anggaran peralatan yang akan digunakan dalam manajemen K3" merupakan strategi yang tergolong dalam kekuatan-ancaman (ST). Biaya peralatan manajemen K3 di TPAS Wisata Edukasi Talangagung telah disediakan oleh DLH Kab. Malang, sehingga secara kuantitas maupun kualitas mencukupi. Pembiayaan merupakan unsur penting dalam penerapan manajemen K3 [22]. Perumusan strategi ini berdasarkan pada kedua faktor lingkungan tersebut, maka mahalnya harga peralatan tidak ditanggung oleh tenaga kerja TPAS Wisata Edukasi Talangagung, melainkan dapat dianggarkan oleh DLH Kab. Malang. Strategi terakhir yaitu "Menyusun peraturan internal terkait manajemen K3". Strategi ini dirumuskan berdasarkan faktor kelemahan dan ancaman, sehingga dikategorikan dalam strategi kelemahanancaman (WT). Adanya ketentuan internal mengenai manajemen K3 akan meningkatkan kepatuhan tenaga kerja dalam manajemen K3 tanpa adanya tenaga ahli K3 dan pelatihan manajemen K3 [23][24]. Serta akan menghindari tidak adanya peraturan manajemen K3 di lingkungan kerja TPAS Wisata Edukasi Talangagung.

\section{Penentuan Strategi Prioritas}

Keempat alternatif strategi yang telah dirumuskan, tidak dapat dijalankan secara bersamaan, karena tidak dapat berjalan secara maksimal. Oleh karena itu, perlu adanya penentuan strategi prioritas berdasarkan hasil skor pada masing-masing faktor lingkungan yang memiliki relevansi dalam komponen perumusan strategi [25][26]. Hasil penentuan strategi prioritas dapat dilihat pada Tabel 4. 
Tabel 4. Hasil penentuan strategi prioritas

\begin{tabular}{lccc}
\hline \multicolumn{1}{c}{ Alternatif Strategi } & Faktor Lingkungan & Skor & Ranking \\
\hline $\begin{array}{l}\text { Meninjau peralatan yang akan digunakan dalam } \\
\text { implementasi OHS }\end{array}$ & S2, S3, O1, O2 & 2,022 & 3 \\
$\begin{array}{l}\text { Meningkatkan kesadaran manajemen K3 } \\
\begin{array}{l}\text { Penetapan anggaran peralatan yang akan digunakan dalam } \\
\text { manajemen K3 }\end{array}\end{array}$ & W1, W2, O1, O2 & 2,213 & 1 \\
Menyusun peraturan internal terkait manajemen K3 & W1, S4, T1 & 2,048 & 2 \\
\hline
\end{tabular}

Sumber: Hasil analisis, 2019

\section{Perencanaan Implementasi Strategi}

Peningkatan kesadaran manajemen K3 merupakan strategi prioritas membutuhkan perencanaan dalam implementasinya. Kesadaran dalam K3 oleh tenaga kerja akan berdampak besar dalam penerapan manajemen K3 secara menyeluruh [27][28][29][30]. Perencanaan ini terbagi atas program, kegiatan, dan luaran. Perencanaan ini akan membantu implementasi strategi berjalan maksimal pada lingkungan kerja. Hasil perencanaan implementasi strategi tertera pada Tabel 5.

Tabel 5. Hasil perencanaan implementasi strategi

\begin{tabular}{|c|c|c|c|}
\hline Strategi & Program & \multirow{2}{*}{$\begin{array}{c}\text { Kegiatan } \\
\text { Perekrutan tenaga ahli K3 }\end{array}$} & Output \\
\hline $\begin{array}{l}\text { Meningkatkan } \\
\text { terhadap kesadaran } \\
\text { risiko K3 }\end{array}$ & $\begin{array}{l}\text { Peningkatan kuantitas } \\
\text { tenaga kerja dalam } \\
\text { manajemen risiko K3 }\end{array}$ & & $\begin{array}{l}\text { Adanya tenaga ahli K3 } \\
\text { dalam lingkungan kerja }\end{array}$ \\
\hline & $\begin{array}{l}\text { Peningkatkan kualitas } \\
\text { tenaga kerja dalam } \\
\text { manajemen risiko K3 }\end{array}$ & $\begin{array}{l}\text { Pelatihan } \\
\text { risiko K3 }\end{array}$ & $\begin{array}{l}\text { Meningkatnya } \\
\text { pemahaman tenaga kerja } \\
\text { terhadap manajemen } \\
\text { risiko K3 yang dilakukan } \\
\text { dalam periode yang } \\
\text { panjang }\end{array}$ \\
\hline & & $\begin{array}{l}\text { Briefing sebelum kegiatan } \\
\text { dimulai }\end{array}$ & $\begin{array}{l}\text { Meningkatnya } \\
\text { pemahaman tenaga kerja } \\
\text { terhadap manajemen } \\
\text { risiko K3 yang dilakukan } \\
\text { dalam periode yang } \\
\text { singkat }\end{array}$ \\
\hline & $\begin{array}{l}\text { Kampanye } \\
\text { penerapan } \\
\text { risiko K3 }\end{array}$ & $\begin{array}{l}\text { Penghargaan terhadap } \\
\text { tenaga kerja dalam } \\
\text { penerapan manajemen } \\
\text { risiko K3 }\end{array}$ & $\begin{array}{l}\text { Tenaga } \\
\text { meningkatkan penerapan } \\
\text { manajemen risiko K3 di } \\
\text { lingkungan kerja }\end{array}$ \\
\hline & & $\begin{array}{l}\text { Pemberian sanksi bagi } \\
\text { tenaga kerja yang } \\
\text { melanggar } \\
\text { risiko K3 }\end{array}$ & $\begin{array}{l}\text { Tenaga kerja tidak } \\
\text { mengulangi kesalahannya } \\
\text { kembali }\end{array}$ \\
\hline
\end{tabular}

Sumber: Hasil analisis, 2019

\section{Manajemen K3 Operasional TPAS Wisata Edukasi Talangagung}

Talangagung merupakan salah satu TPAS terbaik dalam pengelolaan lingkungan, sehingga menjadi salah satu sarana edukasi bagi masyarakat [31]. Penerapan manajemen K3 kepada tenaga kerja merupakan salah satu faktor pendukung dalam peningkatan pelayanan kepada pengunjung yang disertai dengan peningkatan produktivitas tenaga kerja selama berada pada wilayah kerja [32][33]. Meningkatnya produktivitas tenaga kerja melalui manajemen K3 akan meningkatkan operasional TPAS Wisata Edukasi dalam pemrosesan sampah, sehingga dampak lingkungan yang ditimbulkan akibat keberadaan TPAS dapat diminimalisir [34][35].

\section{Kesimpulan}

TPAS Wisata Edukasi Talangagung perlu adanya pelaksanaan dan pengelolaan manajemen K3 yang telah diterapkan selain merumuskan manajemen K3 yang baru, sebagai penyempurnaan. Perumusan strategi alternatif dalam manajemen K3 TPAS Wisata Edukasi Talangagung 4 alternatif strategi. Strategi prioritas yaitu "peningkatan kesadaran terhadap manajemen K3" dimana terdapat perencanaan implementasi strategi untuk memudahkan implementasi strategi pada lingkungan kerja. Perubahan 
implementasi dapat dilakukan jika strategi tersebut tidak berjalan secara optimal. Penerapan manajemen K3 di TPAS Wisata Edukasi Talangagung saat ini belum berjalan secara maksimal, sehingga perlu adanya perhatian stakeholder. Saran untuk penelitian selanjutnya yaitu perlu melibatkan tenaga ahli K3 dari pemerintah, akademisi, maupun swasta dalam manajemen K3 TPAS Wisata Edukasi Talangagung.

\section{Ucapan Terima Kasih}

Peneliti mengucapkan terimakasih kepada DLH Kab. Malang selaku pengelola TPAS Wisata Edukasi Talangagung beserta seluruh tenaga kerja TPAS Wisata Edukasi Talangagung atas kerja samanya dalam membantu pencapaian penelitian ini.

\section{Referensi}

[1] E. Munawar, Y. Yunardi, J. Fellner, and L. Johann. "The development of landfill operation and management in Indonesia," J. Mater. Cycles Waste Management Vol. 20 (2), hal. 1128-1142, 2017.

[2] H. Sudibyo, Y. S. Pradana, A. Budiman, and W. Budhijanto, "Municipal solid waste management in Indonesia - A study about selection of proper solid waste reduction method in D.I. Yogyakarta Province," World Engineers Summit - Applied Energy Symposium \& Forum: Low Carbon Cities \& Urban., Singapore 494-499, 2017.

[3] Kasam, "Analisis Resiko Lingkungan Pada Tempat Pembuangan Akhir (TPA) Sampah (Studi Kasus: TPA Piyungan Bantul)," J. Sains dan Teknologi Lingkungan, Vol. 3 (1), hal. 19-30, 2016.

[4] M. Vaverkova and A. Dana, "Evaluation of Landfill Pollution with Special Emphasis On Heavy Metals," J. of Ecological Engineering, Vol. 15 (2), pp. 1-6. 2014

[5] Wardhayani, Sutji., Setiani, Onny., \& Hanani, Yusniar. 2006. Analisis Risiko Pencemaran Bahan Toksik Timbal (Pb) Pada Sapi Potong Di Tempat Pembuangan Akhir (TPA) Sampah Jatibarang Semarang. Jurnal Kesehatan Lingkungan Vol. 5 (1): 11-16.

[6] P. Pam, H. Andrew and H. Dennis, "Development of A Global Framework for OHS Professional Practice," Safety Science Vol. 117: 404-416, 2016.

[7] L. S. Robson, B. C. Amick III, C. Moser, M. Pagell, E. Mansfield, H. S. Shannon, M. B. Swift, S. H. Johnson, S. Cardoso, and H. South, "Important Factors in Common Among Organizations Making large Improvement in OHS Performance: Results of An Exploratory Multiple Case Study," Safety Science, Vol. 86, pp. 211-227, 2016.

[8] J. Kassu and K. Daniel, "Industrial Occupational Safety and Health Innovation for Sustainable Development," Engineering Science and Technology, an Int. J., Vol. 20, pp. 372-380, 2016.

[9] I. Mitrady, H. K. Daryanto, and A. Maulana, "Loan Distribution Strategy PT Bank X (Persero), TBK - Bogor Credit Business Unit," J. Aplikasi Bisnis dan Manajemen, Vol. 1 (2), hal. 98-107, 2015.

[10] Luntungan, Warren G. A., Tawas, Hendra N., "Strategi Pemasaran Bambuden Boulevard Manado: Analisis SWOT," JURNAL EMBA: J. Riset Ekonomi, Manajemen, Bisnis dan Akuntansi, Vol. 7 (4), hal. 5495-5504, 2019.

[11] D. M. Kusumawardani dan E. Sediyono, "Sistem Informasi Manajemen Rantai Pasok Pariwisata untuk Pembuatan Produk Wisata pada Agen Tour \& Travel dengan Analisis SWOT dan Metode Analytic Network Process (ANP),” J. Sistem Informasi Bisnis, Vol. 2, hal. 177-185, 2016

[12] E. Triana, "Analisa Sistem Pendistribusian Produk Jadi di PT. Perkebunan Nusantara V Riau dengan Menggunakan Metode SWOT," INOVBIZ Vol. 7, hal. 220-225, 2019.

[13] A. Y. Syamsuri dan S. A. Ikat, "SWOT Analysis of Waterfront City; The Development Concept in Palangka Raya," JEJAK Vol. 12 (2): 403-420, 2019.

[14] P. T. Suwarno, "Analisis SWOT Balanced Scorecard (BSC) dalam Kebijakan Pengembangan UMKM Batik Suminar di Kabupaten Kediri," E-Jurnal Ekonomi dan Bisnis Universitas Udayana. Vol. 9 (7), hal. 653-670, 2020.

[14] S. Hidayat, A. P. Rumengan, S, Darwisito, M. Opmi, W. M. Mingkid, B. T. Wagey, dan C. P. Paruntu, "Studi Perumusan Strategi Pengelolaan Ekowisata Bahari Kota Manado di Era Revolusi Industri 4.0 Berdasarkan Analisis SWOT," J. Pesisir dan Laut Tropis, Vol. 7 (3), hal. 142-156, 2019.

[15] E. K. Novitasari, D. Hermanuadi dan A. Brilliantina, "Application of SWOT and ANP Methods in Order to Select the Agroindustrial Development Strategy Based On Tapai in Bondowoso," Food Scientech J., Vol. 2 (2), hal. 62-68, 2020.

[16] S. J. Yoon, H. K. Lin, G. Chen, S. Yi, J. Choim, Rui and Zhenzua, "Effect of Occupational Health and Safety Management System on Work-Related Accident Rate and Differences of Occupational Health and Safety Management System Awareness between Managers in South Korea's Construction Industry," Safety and Health at Work, Vol. 4 (4), hal. 201-209, 2013. 
[17] O. Gottfried, D. D. Clercq, E. Blair, X. Weng and C. Wang, "SWOT-AHP-TOWS Analysis of Private Investment Behavior in The Chinese Biogas Sector," J. of Cleaner Production Vol. 184 632647, 2018.

[18] R. Parmawati, A. S. Leksono, B. Yanuwiadi and A. S. Kurnianto, "Exploration of marine Tourism in Watulimo, Trenggalek Regency: Challenges, Potentials, and Development Strategies. Strategies," J. of Indonesia Tourism and Development Studies, Vol.5 (3), pp. 175-184, 2017.

[19] S. I. Azubuike, O. Songi, M. Irowarisima and J. K. Chinda, "Identifying Policy and Legal Issues for Shale Gas Development in Algeria: A SWOT Analysis," The Extractive Industries and Society Vol. 5, pp. 469-480, 2018.

[20] M. Yona dan A. Wulandari, "Pengaruh Gaya Kepemimpinan, Pelatihan, dan Program Keselamatan dan Kesehatan Kerja Terhadap Produktifitas Kerja Karyawan PT. Ersyah Sejati," BENING, Vol. 7 (1), hal. 31-42, 2020.

[21] T. S. Utami dan M. Nanda, "Pengaruh Pelatihan Bencana dan Keselamatan Kerja Terhadap Respons Persepsi Mahasiswa Prodi Ilmu Kesehatan Masyarakat," J. JUMANTIK Vol. 4 (1), hal. 83-100, 2019.

[22] F. Abbas, I. Oppier dan C. G. Buyang, "Analisis Penerapan Keselamatan dan Kesehatan Kerja Terhadap Biaya Proyek Konstruksi Bangunan Gedung di Kota Ambon," J. Simetrik Vol. 9 (2), hal. 242-249, 2019.

[23] J. Fardinal, H. Nizwardi, "Hubungan Pemahaman Keselamatan dan Kesehatan Kerja (K3), Kedisiplinan Mahasiswa, dan Bimbingan Dosen Terhadap Unjuk Kerja Praktik Mahasiswa Program Studi Teknik Mesin Politeknik Negeri Padang," J. Teknik Mesin, Vol. 11 (2), hal. 58-62, 2018.

[24] S. Narulita dan D. A. Nugroho, "Hubungan Pengetahuan Keselamatan Kerja dengan Tingkat Kepatuhan SOP Pekerja Forklift," J. Dunia Kesmas, Vol. 8 (2), hal. 95-99, 2019.

[25] R. Sinulingga, M. Baiquni dan S. Purnama, "Pengelolaan Sumberdaya Air Untuk Pengembangan Pariwisata di Pulau Pari, Kepulauan Seribu, DKI Jakarta," J. Majalah Geografi Indonesia, Vol. 29 (2), hal. 177-186, 2015.

[26] P. S. Rejeki dan F. H. Mardiansjah, "Analisis Prioritas Strategi Pengembangan Kawasan Pertanian Padi Berbasis Preferensi Petani di Kabupaten Kendal," J. Pembangunan Wilayah dan Kota Vol. 14 (3): 187-198, 2018.

[27] S. Muflihah dan H. S. Pudjiahrdjo, "Analisis Manajemen Risiko Keselamatan dan Kesehatan Kerja (K3) pada Proyek Pembangunan Gedung di Semarang," Teknika Vol. 1 (1), 2017.

[28] D. I. Handayani dan T. Prihatiningsih, "Multi Kriteria Terhadap Penilaian Penyebab Kejadian Risiko Kecelakaan Kerja untuk Proyek Konstruksi dengan Metode Analytical Network Process," J@ti Undip: J. Teknik Industri, Vol. 13 (1), hal. 27-36, 2018.

[29] A. A. Tantia, S. Jayanti dan Ekawati, "Gambaran Manajemen Pengendalian Risiko Paparan Lingkungan Kerja di Area Terbuka dalam Pencegahan Penyakit Akibat Kerja (Studi Kasus di Perusahaan Konstruksi PT. X),” J. Kesehatan Masyarakat, Vol. 4 (4), hal. 619-629, 2016.

[30] S. Sunarto, M. Bisri, Soemarni dan Suyadi, "Influencing factor on society behavior towards household waste management in Tulungagung," American J. of Sociological Research, Vol. 4 (4), hal. 113-122, 2014.

[31] S. Koderi, A. Said dan A. W. Muahimin, "Knowledge, Action, Perception and Attitude of Management of Talangagung Landfill toward Edu-Tourism Program: A Community Perspective," J. of Indonesian Tourism and Development Studies, Vol. 6 (1), hal. 41-48, 2018.

[32] R. R. Agustini dan D. Rimantho, "Gambar Penentuan Prioritas Strategi Pengelolaan K3 Proyek Pemasangan Pipa Gas Menggunakan Pendekatan Metode AHP," J. Teknik Industri, Vol. 19 (2), hal. 107-117, 2018.

[33] I. Mindhayani, "Penyuluhan Keselamatan dan Kesehatan Kerja (K3) di UD. Barokah Bantul." J. Berdaya Mandiri, Vol. 1 (1), hal. 78-83, 2019.

[34] M. J. Svendsen, K. G. Scmidt, A. Holtermann and C. D. N. Rasmussen, "Expert Panel Survey Among Occupational Health and Safety Professionals in Denmark for Prevention and Handling of Musculoskeletal Disorders at Workplaces," Safety Science, Vol. 131, 2020.

[35] A. G. Nurkhlolis, "Pengendalian Bahaya Kerja dengan Metode Job Safety Analysis pada Penerimaan Afval Lokal Bagian Warehouse di PT. ST,” Engineering and Sains J., Vol. 1 (1), hal. 11-16, 2017. 